\title{
Arthritis, osteomyelitis, septicemia and meningitis caused by Klebsiella in a low-birth-weight newborn: a case report
}

\author{
Ziaaedin Ghorashi', Nariman Nezami ${ }^{2^{*}}$, Hamideh Hoseinpour-feizi ${ }^{1}$, Sona Ghorashi ${ }^{3}$ and Jafar Sadegh Tabrizi ${ }^{4}$
}

\begin{abstract}
Introduction: Klebsiella pneumoniae is in most cases a hospital-acquired infection and presents as pneumonia, septicemia and meningitis in patients with some predisposing factors, including prematurity, intravenous catheter, history of antibiotic therapy and intravenous nutrients.

Case presentation: A low-birth-weight, 33-day-old Caucasian girl with respiratory distress syndrome was admitted to our hospital. She developed septicemia, meningitis, polyarticular arthritis and osteomyelitis by nosocomial $K$. pneumoniae which was resistant to most antibiotics except ciprofloxacin. She was therefore treated with ciprofloxacin and co-trimoxazole for eight weeks. After completion of the treatment course, she completely improved with excellent weight gain and without any adverse effects during three years of follow-up.
\end{abstract}

Conclusion: In the resistant strain of $K$. pneumoniae, ciprofloxacin could be considered as a therapeutic option with the prospect of a good outcome, even in neonates and infants.

\section{Introduction}

Pneumonia is a type of infection that is most commonly caused outside the hospital by Klebsiella pneumoniae [1]. Mostly, K. pneumoniae is recognized as a hospitalacquired infection presenting as pneumonia, septicemia and meningitis in patients with some predisposing factors (including prematurity, intravenous catheter, history of antibiotic therapy and intravenous nutrients) [2,3]. In the rare patients with underlying conditions among newborns and older adults, $K$. pneumoniae may result in arthritis and osteomyelitis. All Klebsiella subtypes are resistant to ampicillin, especially multi-drug-resistant (MDR) subtypes which are resistant to the majority of antibiotics, except fourth-generation cephalosporins and carbapenems. Previously, patients with MDR subtype infections usually received first-generation cephalsporins and aminoglycosides.

\footnotetext{
* Correspondence: Dr.nezami@gmail.com

${ }^{2}$ Drug Applied Research Center, Tabriz University (Medical Sciences), Tabriz, Iran

Full list of author information is available at the end of the article
}

\section{Case presentation}

A 33-day-old Caucasian girl was brought to the Tabriz Children's Hospital with poor breastfeeding, recurrent vomiting and anorexia. She was admitted with a primary diagnosis of septicemia.

She was born from a mother with pre-eclampsia through normal vaginal delivery at the 34th week of gestation, with a birth weight of 1670 g. Her Apgar scores at one and five minutes were five and six, respectively. During delivery and before admission to the Tabriz Children's Hospital, she had been hospitalized in the Talegani neonatal intensive care unit for prematurity, septicemia, respiratory distress syndrome and gastrointestinal bleeding. In Talegani Hospital, she had received antibiotic therapy, including ampicillin and gentamicin, then her medication was changed to cefotaxime and vancomycin, and finally her treatment continued with intravenous immunoglobulin, imipenem and ceftazidime.

Her physical examination revealed that she was pale, cachectic, anorexic and hypotonic, and her Moro and sucking reflexes were weak. She also exhibited grunting and had substernal and intercostal retraction. The patient's body weight, height and head circumference were $1700 \mathrm{~g}, 43 \mathrm{~cm}$ and $31 \mathrm{~cm}$, respectively. Her vital

\section{Biomed Central}


signs, including pulse rate, respiratory rate, body temperature, $\mathrm{O}_{2}$ saturation under the oxygen hood and without using the oxygen hood were $158 / \mathrm{min}, 48 / \mathrm{min}$, $38.6^{\circ} \mathrm{C}, 95 \%$ and $89 \%$, respectively.

Her cerebrospinal fluid (CSF) was purulent, and CSF analysis showed $520 \mathrm{mg} / \mathrm{dL}$ protein; $16 \mathrm{mg} / \mathrm{dL}$ glucose; many white blood cells (WBCs), with $85 \%$ polymorphonuclear cells and 15\% lymphocytes; and 25 red blood cells $(\mathrm{RBCs}) / \mathrm{mm}^{3}$. The results of the other laboratory tests are shown in Table 1 . In the CSF and blood culture, K. pneumonia was resistant to most of the antibiotics and sensitive only to ciprofloxacin and cotrimoxazole. Her chest X-ray showed bilateral humeral osteomyelitis and bilateral glenohumeral joint arthritis (Figure 1).

On the basis of the paraclinical evidence, diagnoses of K. pneumoniae septicemia, meningitis, arthritis and osteomyelitis were made, and a treatment protocol with a combination of intravenous ciprofloxacin and co-trimoxazole antibiotics was started (for 28 days). At the end of the intravenous treatment period, she weighed $2420 \mathrm{~g}$, and her CSF analysis and culture were within normal range. Afterward, she was discharged with oral ciprofloxacin, co-trimoxazole and rifampicin for another 28 -day period. Figures 2 and 3 show her chest X-rays obtained on the seventh and 28th days of oral antibiotic therapy, respectively. At the end of 28 days of oral antibiotic therapy (when the patient was 88 days old), her weight had reached $4250 \mathrm{~g}$ and normal glenohumeral joints and humerus bones were shown on her chest Xray. During three years of follow-up, she had normal developmental milestones and was not readmitted to the hospital.

\section{Discussion}

Prolonged hospital stay, decreased gestational age, prolonged use of broad-spectrum antibiotics and

Table 1 Laboratory tests and results on admission ${ }^{a}$

\begin{tabular}{|c|c|c|c|c|c|}
\hline Complete blood & ll count & Biochemical & & Arterial blood & gas \\
\hline $\begin{array}{l}\text { WBC count (cells/ } \\
\mu \mathrm{L})\end{array}$ & 6500 & $\begin{array}{l}\text { FBG (mg/ } \\
\mathrm{dL})\end{array}$ & 42 & $\mathrm{pH}$ & 7.29 \\
\hline $\mathrm{Hb}, \mathrm{g} / \mathrm{Dl}$ & 7.8 & $\mathrm{Cr}(\mathrm{mg} / \mathrm{dL})$ & 0.5 & $\begin{array}{l}\mathrm{HCO}_{3}{ }^{-} \text {(mmol/ } \\
\mathrm{L})\end{array}$ & 20 \\
\hline Platelets, $n / \mu \mathrm{L}$ & $\begin{array}{l}773 \times \\
10^{3}\end{array}$ & $\begin{array}{l}\text { BUN (mg/ } \\
\mathrm{dL})\end{array}$ & 24 & $\mathrm{PCO}_{2}(\mathrm{mmHg})$ & 43 \\
\hline PMN cells, \% & 51 & & & & \\
\hline Eosinophils, \% & $1 \%$ & Electrolytes & & Other & \\
\hline Lymphocytes, \% & $24 \%$ & $\mathrm{Na}(\mathrm{mEa} / \mathrm{L})$ & 136 & CRP & $2+$ \\
\hline Monocytes, \% & $2 \%$ & $\mathrm{~K}(\mathrm{mEa} / \mathrm{L})$ & 45 & Blood group & $\mathrm{A}^{+}$ \\
\hline Band cells, \% & $21 \%$ & $\mathrm{Ca}(\mathrm{mg} / \mathrm{dL})$ & 10.8 & & \\
\hline
\end{tabular}

${ }^{\mathrm{a}} \mathrm{WBC}$, white blood cells; $\mathrm{Hb}$, hemoglobin; PMN, polymorphonuclear cells; CRP, C-reactive protein; $\mathrm{Na}$, sodium; $\mathrm{K}$, potassium; BUN, blood urea nitrogen; FPG, fasting plasma glucose; $\mathrm{Ca}$, calcium

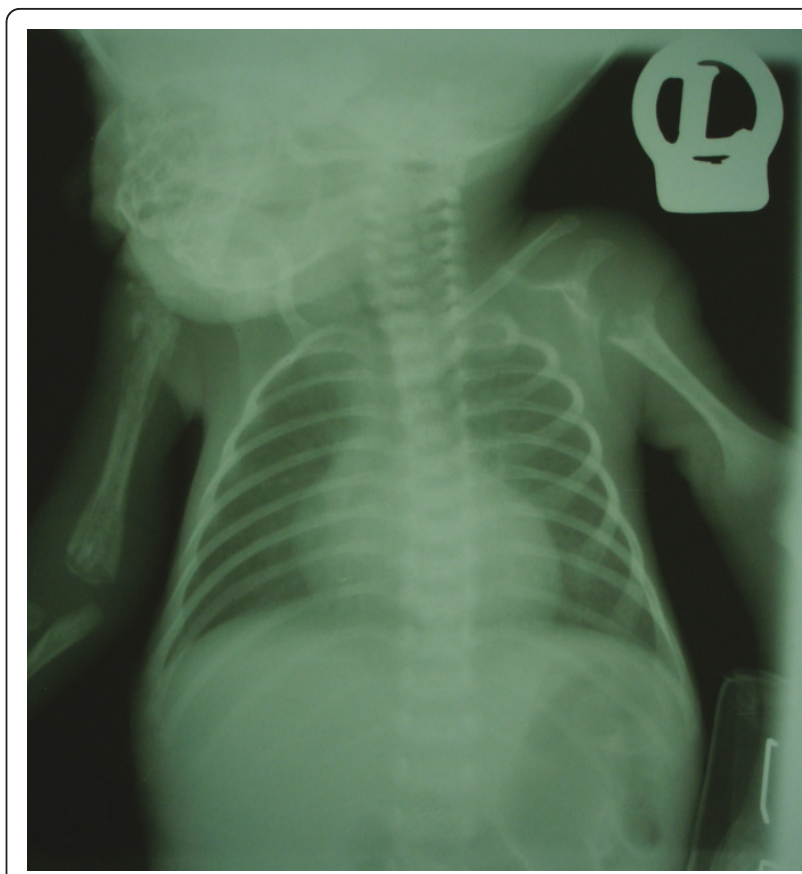

Figure 1 Chest X-ray obtained at the time of admission. Bilateral osteomyelitis in the humerus presented as osteolysis and involucrum. Also, there is sequestration because of osteonecrosis and a pathologic fracture in the proximal part of the humerus. Dislocation of right glenohumeral joint brings up the arthritis diagnosis. There is complete osteolysis in proximal metaphysis in the left humerus and arthritis in the left glenohumeral joint. The heart, lung and pleural space have a normal appearance, while the thymus is atrophic.

inadequacy of some basic facilities and staffing carry the risk of introduction of resistant hospital pathogens [4-6]. In the present case, all of the above-mentioned factors, combined with prematurity, predisposed the neonate to a higher risk of contracting nosocomial $K$. pneumoniae arthritis, osteomyelitis, septicemia and meningitis, although the common cause of osteoarthritis is Grampositive cocci [7].

Adeyemo et al. [8] reported an outbreak of bone infections associated with neonatal septicemia by $K$. pneumoniae in 12 neonates over a six month period at the Special Care Baby Unit, University College Hospital, Ibadan, Nigeria. All patients had septic arthritis, 10 of them had osteomyelitis and $50 \%$ had multiple-joint involvement.

Hospital-acquired $K$. pneumoniae has been reported to be resistant to multiple antibiotics [8,9]. In addition, Ghahramani and Nahaie [10] showed that K. pneumoniae is the most common cause of septicemia in the neonatal ward of the Tabriz Al-Zahra Gynecology and Obstetrics Referral Hospital in Tabriz, Iran.

The parenteral third-generation cephalosporins appear to be a major therapeutic advance in the 


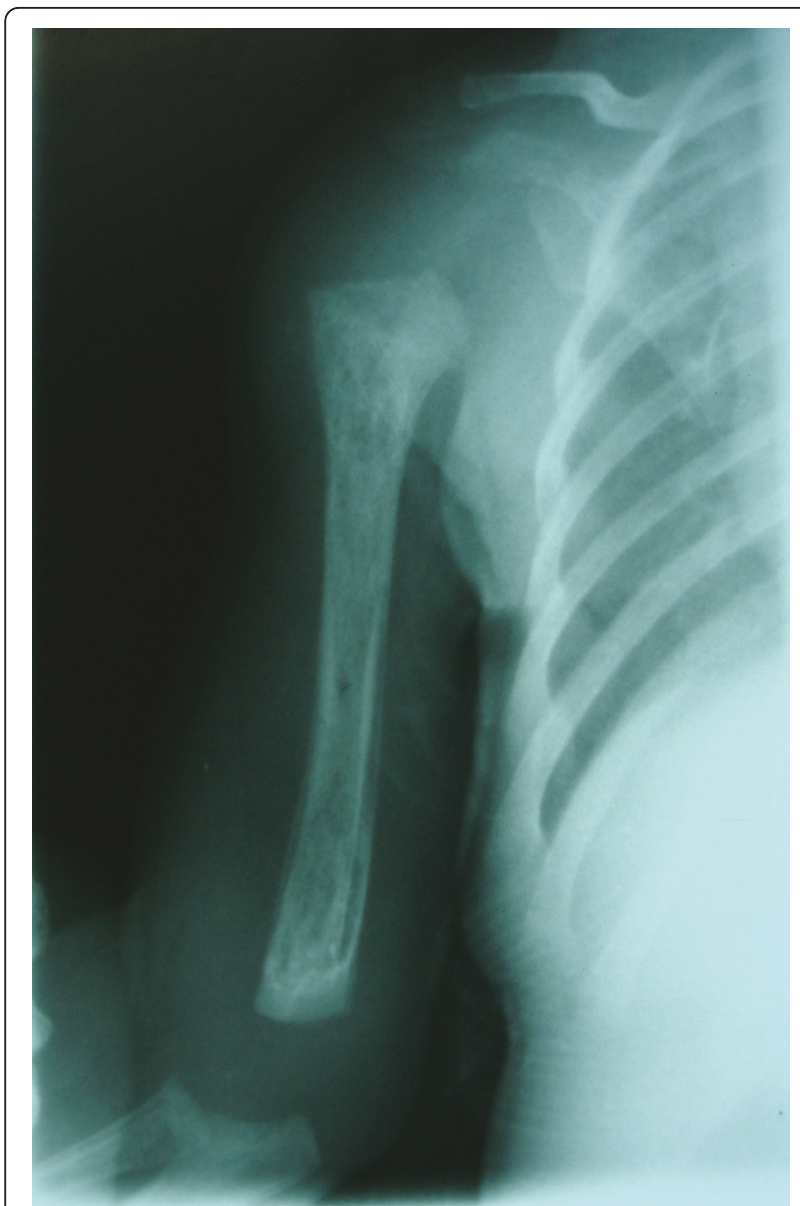

Figure $\mathbf{2}$ Chest X-ray obtained on the seventh day of oral antibiotic therapy. The lytic lesions in the proximal and distal metaphysis in the right humerus are shown.

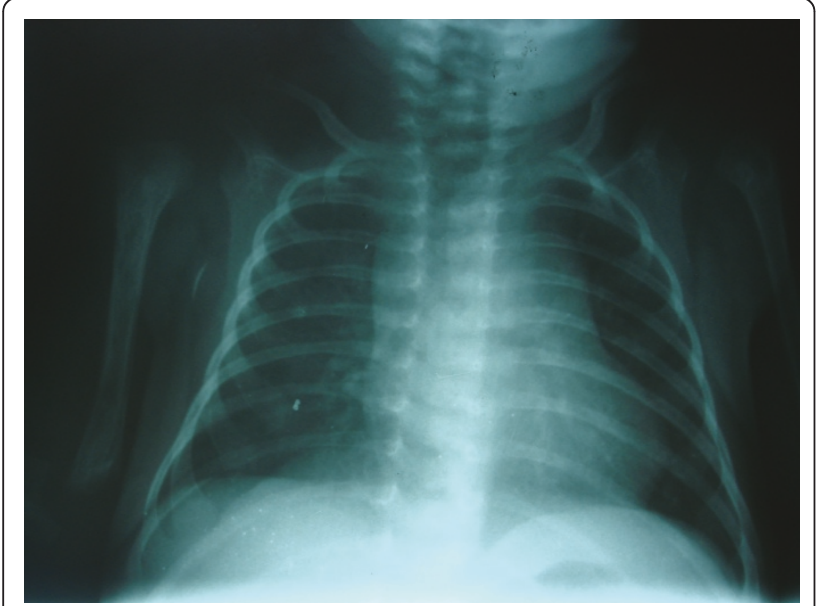

Figure 3 Chest X-ray showing complete resolution of symptoms at the end of anti-biotic therapy. treatment of $K$. pneumoniae [11], but reports of highly resistant strains that produce plasmid-mediated, extended-spectrum $\beta$-lactamases influenced therapeutic outcomes again [12]. Evidence revealed that K. pneumoniae infection, especially the nosocomial type, is resistant to the majority of antibiotics except for ciprofloxacin and ofloxacin [13]. In the present case report, the isolated $K$. pneumoniae was resistant to most of the antibiotics except ciprofloxacin and co-trimoxazole. Therefore, these two antibiotics were used in the treatment protocol. Because of the quinolone cartilage toxicity potential in experimental juvenile animal models, the use of ciprofloxacin among children has been restricted $[13,14]$. However, recent data from Bayer's ciprofloxacin clinical trials database indicate that the role of fluoroquinolones in the treatment of certain serious infections in children does not appear to be compromised by safety concerns when used appropriately [15]. In such cases, when a micro-organism is resistant to all antibiotics except ciprofloxacin, a dosage of 15 $\mathrm{mg} / \mathrm{kg} /$ day to $30 \mathrm{mg} / \mathrm{kg} /$ day is advised in neonates [16].

After completion of the treatment course, our patient completely improved and achieved normal developmental milestones and weight gain, without adverse effects or hospital readmission during three years of follow-up.

\section{Conclusion}

In neonates with delivery problems, prematurity, low birth weight and prolonged hospital admission, nosocomial $K$. pneumoniae should be considered in the differential diagnosis of septicemia, arthritis, osteomyelitis and meningitis. Considering the multi-drug resistance of nosocomial $K$. pneumoniae and sensitivity to quinolones, ciprofloxacin, when used appropriately, should be considered a therapeutic option with good outcomes in patients with serious infections with resistant strains of K. pneumoniae, even in neonates and infants.

\section{Consent}

Written informed consent was obtained from the patient's next-of-kin for publication of this case report and any accompanying images. A copy of the written consent is available for review by the Editor-in-Chief of this journal.

\section{Abbreviations}

CSF: cerebrospinal fluid; MDR: multi-drug-resistant.

\section{Acknowledgements}

The authors acknowledge the parents of the patient for their collaboration and consent.

\section{Author details}

'Department of Pediatrics, Tabriz University (Medical Sciences), Tabriz, Iran. ${ }^{2}$ Drug Applied Research Center, Tabriz University (Medical Sciences), Tabriz, Iran. ${ }^{3}$ Young Researchers Club, Tabriz Branch, Islamic Azad University, Tabriz, 
Iran. ${ }^{4}$ Faculty of Health and Nutrition, Tabriz University of Medical Sciences, Tabriz, Iran.

\section{Authors' contributions}

$\mathrm{ZG}, \mathrm{HH}$ and SG collected the patient data and participated in the patient's hospitalization and treatment process. NN was a major contributor in writing the manuscript. JST helped to revise and edit the manuscript. All authors read and approved the final manuscript.

\section{Competing interests}

The authors declare that they have no competing interests.

Received: 1 February 2010 Accepted: 27 June 2011

Published: 27 June 2011

\section{References}

1. Donnenberg MS: Enterobacteriaceae. In Mandell, Douglas, and Bennett's Principles and Practice of Infectious Diseases. Volume II.. 6 edition. Edited by: Mandell GL, Bennett JE, Dolin R. New York: Elsevier/Churchill Livingstone; 2005:2567-2586.

2. Feigin RD, Cherry J, Demmler-Harrison GJ, Kaplan SL: Feigin and Cherry's Textbook of Pediatric Infectious Diseases. 5 edition. Philadelphia: Saunders; 2004.

3. Asensio A, Oliver A, González-Diego P, Baquero F, Pérez-Díaz JC, Ros P, Cobo J, Palacios M, Lasheras D, Cantón R: Outbreak of a multiresistant Klebsiella pneumoniae strain in an intensive care unit: antibiotic use as risk factor for colonization and infection. Clin Infect Dis 2000, 30:55-60.

4. Yalaz M, Arslanoğlu S, Çetin H, Aydemir Ş, Tünger A, Akısü M, Kültürsay N: Evaluation of culture-proven sepsis in a level III NICU: a two year analysis. Adnan Menderes Üniversitesi Tip Fakültesi Dergisi 2004, 5:5-9.

5. Turkish Neonatal Society; Nosocomial Infections Study Group: Nosocomial infections in neonatal units in Turkey: epidemiology, problems, unit policies and opinions of healthcare workers. Turk J Pediatr 2010, 52:50-57.

6. Cordero L, Rau R, Taylor D, Ayers LW: Enteric gram-negative bacilli bloodstream infections: 17 years' experience in a neonatal intensive care unit. Am J Infect Control 2004, 32:189-195.

7. Nelson JD, Koontz WC: Septic arthritis in infants and children: a review of 117 cases. Pediatrics 1966, 38:966-971.

8. Adeyemo AA, Akindele JA, Omokhodion SI: Klebsiella septicemia, osteomyelitis and septic arthritis in neonates in Ibadan, Nigeria. Ann Trop Pediatr 1993, 13:285-289.

9. Westbrook GL, O'Hara CM, Roman SB, Miller JM: Incidence and identification of Klebsiella planticola in clinical isolates with emphasis on newborns. J Clin Microbiol 2000, 38:1495-1497.

10. Ghahramani P, Nahaie MR: Klebsiella sepsis in neonates admitted to AlZahra Hospital, Tabriz. Med J Tabriz Univ Med Sci 2002, 35:69-73.

11. Tang LM, Chen ST, Hsu WC, Chen CM: Klebsiella meningitis in Taiwan: an overview. Epidemiol Infect 1997, 119:135-142.

12. Smith CE, Tillman BS, Howell AW, Longfield RD, Jorgensen JH: Failure of ceftazidime-amikacin therapy for bacteremia and meningitis due to Klebsiella pneumoniae producing an extended-spectrum $\beta$-lactamase. Antimicrob Agents Chemother 1990, 34:1290-1293.

13. Akindele JA, Rotilu IO: Outbreak of neonatal Klebsiella septicemia: a review of antimicrobial sensitivities. J Med Sci 1997, 26:51-53.

14. Ingham B, Brentnall DW, Dale EA, McFadzean JA: Arthropathy induced by antibacterial fused $\mathrm{N}$-alkyl-4-pyridone-3-carboxylic acids. Toxicol Lett 1977, 1:21-26.

15. Grady R: Safety profile of quinolone antibiotics in the pediatric population. Pediatr Infect Dis J 2003, 22:1128-1132.

16. Nicholson JF, Pesce MA: Laboratory medicine, drug therapy and reference tables. In Nelson Textbook of Pediatrics.. 17 edition. Edited by: Behrman RE, Kliegman R, Jenson HB. Philadelphia: Saunders; 2004:2393-2505.

doi:10.1186/1752-1947-5-241

Cite this article as: Ghorashi et al: Arthritis, osteomyelitis, septicemia and meningitis caused by Klebsiella in a low-birth-weight newborn: a case report. Journal of Medical Case Reports 2011 5:241.

\section{Submit your next manuscript to BioMed Central and take full advantage of:}

- Convenient online submission

- Thorough peer review

- No space constraints or color figure charges

- Immediate publication on acceptance

- Inclusion in PubMed, CAS, Scopus and Google Scholar

- Research which is freely available for redistribution

Submit your manuscript at www.biomedcentral.com/submit
Biomed Central 